\title{
A Compact Thévenin Model for a Rectenna and Its Application to an RF Harvester with MPPT
}

\author{
Manel Gasulla ${ }^{1, *(0)}$, Edgar Ripoll-Vercellone ${ }^{1,2}\left(\mathbb{D}\right.$ and Ferran Reverter ${ }^{1}(\mathbb{C}$ \\ 1 e-CAT Research Group, Department of Electronic Engineering, Castelldefels School of Telecommunications \\ and Aerospace Engineering, Universitat Politècnica de Catalunya, c/ Esteve Terradas, 7, \\ 08860 Castelldefels (Barcelona), Spain; edgar.ripoll.vercellone@upc.edu (E.R.-V.); \\ ferran.reverter@upc.edu (F.R.) \\ 2 Idneo Technologies, c/ Rec de Dalt s/n., 08100 Mollet del Vallès (Barcelona), Spain \\ * Correspondence: manel.gasulla@upc.edu; Tel.: +34-934-137-092
}

Received: 28 March 2019; Accepted: 3 April 2019; Published: 6 April 2019

check for updates

\begin{abstract}
This paper proposes a compact Thévenin model for a rectenna. This model is then applied to design a high-efficiency radio frequency harvester with a maximum power point tracker (MPPT). The rectenna under study consists of an L-matching network and a half-wave rectifier. The derived model is simpler and more compact than those suggested so far in the literature and includes explicit expressions of the Thévenin voltage $\left(V_{\mathrm{oc}}\right)$ and resistance and of the power efficiency related with the parameters of the rectenna. The rectenna was implemented and characterized from -30 to $-10 \mathrm{dBm}$ at $808 \mathrm{MHz}$. Experimental results agree with the proposed model, showing a linear current-voltage relationship as well as a maximum efficiency at $V_{\mathrm{oc}} / 2$, in particular $60 \%$ at $-10 \mathrm{dBm}$, which is a remarkable value. An MPPT was also used at the rectenna output in order to automatically work at the maximum efficiency point, with an overall efficiency near $50 \%$ at $-10 \mathrm{dBm}$. Further tests were performed using a nearby transmitting antenna for powering a sensor node with a power consumption of $4.2 \mu \mathrm{W}$.
\end{abstract}

Keywords: RF harvesting; rectenna; Thévenin model; maximum power point tracking; MPPT; L-matching network; sensor node

\section{Introduction}

Radio frequency (RF) energy harvesting has been extensively proposed to power tiny devices such as RFID tags, autonomous sensors, or Internet of Things (IoT) nodes. RF energy can be harvested either from dedicated sources, such as in the case of RFID devices [1-4], or from the RF energy already present in the ambient environment and coming from unintentional sources such as TV, FM radio, cellular, or WiFi emitters [2,5-10].

Figure 1 shows the block diagram of an RF harvester powering a sensor node. The rectenna (rectifying antenna) transforms the RF signal to a DC voltage and the maximum power point tracker (MPPT) provides the optimum load to the rectenna to transfer the maximum power to the sensor node.

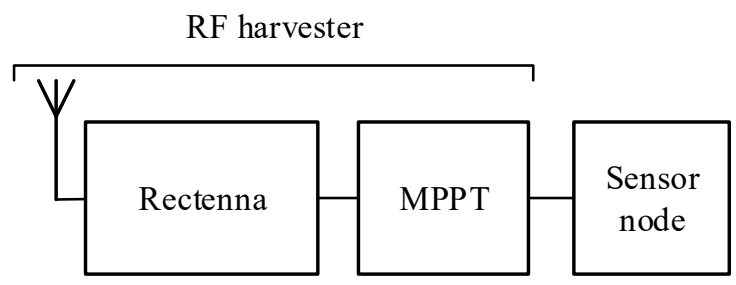

Figure 1. Block diagram of a radio frequency $(\mathrm{RF})$ harvester powering a sensor node. 
The rectenna is composed of an antenna, an impedance matching network, and a rectifier. As the available power at the antenna decreases so does the generated voltage. Whenever this voltage is not high enough to properly bias the diodes of the rectifier, power efficiency severely decreases. Several techniques have been proposed to increase the efficiency at low power levels. One of them consists of using an L-matching network for boosting the voltage at the rectifier input [1,3,5,10-21]. As for the MPPT, several works propose its use with rectennas using either commercial chips $[6,7]$ or ad hoc designs [22-25].

With the aim of gaining more insight into the performance of the rectennas, different analytical models are proposed. However, the derived expressions, which in some cases seek to model the rectenna output as an equivalent Thévenin circuit, are rather complex and may require additional simulations or extensive calculations, which hide the influence of the different parameters of the rectenna on its performance [12,18,26-28]. At the other extreme, the Thévenin parameters are sometimes inferred by experimental characterization [25,29-32]. However, in these cases no relationship with the rectenna parameters is established.

Taking into account the previous limitations, this paper proposes a compact Thévenin model for the rectenna with the benefit of achieving manageable expressions of the Thévenin parameters as a function of the parameters of the rectenna so as to gain insight into its operation. In particular, the rectenna under study consists of an L-matching network and of a half-wave rectifier. The proposed model is then experimentally verified and the rectenna further tested in a high-efficency RF harvester with MPPT.

The paper, which continues and expands the work presented in [32], is organized as follows. Section 2 presents the rectenna and the derived Thévenin equivalent. Section 3 describes the MPPT and the sensor node. Section 4 presents the materials and methods and Section 5 provides the experimental results and discussions. Finally, Section 6 concludes the work. Complementarily, two appendices are included. Appendix A presents an analytical development useful for the derivation of the Thévenin equivalent and Appendix B shows simulations of the rectenna with and without the matching network.

\section{Rectenna and Its Thévenin Model}

Figure 2 shows the schematic circuit of the rectenna under study [33], which includes a high-pass L-matching network (composed of a capacitor $C_{\mathrm{m}}$ and an inductor $L_{\mathrm{m}}$ ), a half-wave rectifier, and an output filtering capacitor $\left(C_{\mathrm{o}}\right)$. The antenna is modelled by a sinusoidal voltage source $v_{\mathrm{a}}$ of amplitude $V_{\text {ap }}$ and frequency $f_{\mathrm{o}}$ with a series radiation resistance $R_{\mathrm{a}}$. On the other hand, $v_{\text {in }}, Z_{\text {in }}$, and $P_{\text {in }}$ are, respectively, the sinusoidal voltage, impedance, and power at the input of the rectifier, $i_{\mathrm{d}}$ is the diode current, and $V_{\mathrm{O}}, I_{\mathrm{O}}$, and $P_{\mathrm{o}}$ are, respectively, the DC voltage, current, and power at the rectenna output. An equivalent resistance $R_{\mathrm{o}}$ is defined as $V_{\mathrm{o}} / I_{\mathrm{o}}$.

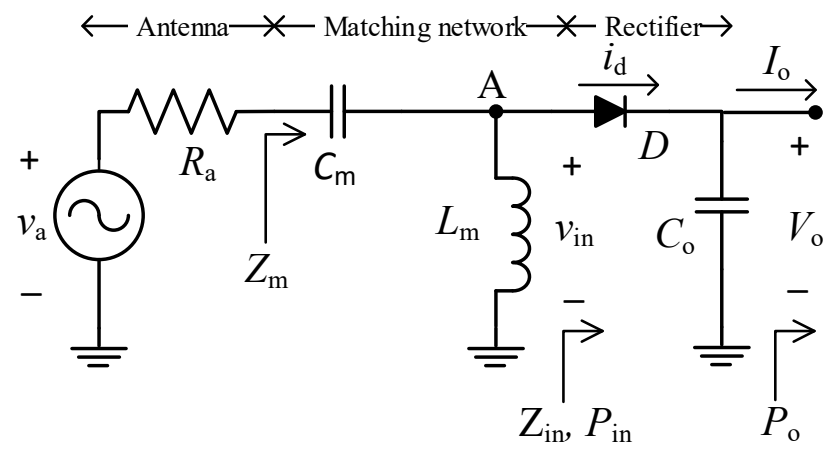

Figure 2. Schematic circuit of the rectenna under study.

The amplitude $V_{\text {ap }}$ is given by [12] as follows:

$$
V_{\mathrm{ap}}=2 \sqrt{2 R_{\mathrm{a}} P_{\mathrm{av}}},
$$


where $P_{\mathrm{av}}$ is the available power at the antenna. The matching network, at matching conditions, that is, $Z_{\mathrm{m}}=R_{\mathrm{a}}$ (where $Z_{\mathrm{m}}$ is defined in Figure 2), boosts the voltage at the input of the rectifier by a voltage gain, $G_{t}$, given by [33] as follows:

$$
G_{\mathrm{t}}=\frac{V_{\mathrm{inp}}}{V_{\mathrm{ap}}}=\frac{1}{2} \sqrt{\left(1+Q^{2}\right)},
$$

where $V_{\text {inp }}$ is the voltage amplitude of $v_{\text {in }}$ and $Q$ is the circuit quality factor given by:

$$
Q=\frac{1}{\omega_{\mathrm{o}} C_{\mathrm{m}} R_{\mathrm{a}}}
$$

where $\omega_{\mathrm{o}}=2 \pi f_{\mathrm{o}}$. On the other hand, the value of $L_{\mathrm{m}}$ must comply:

$$
L_{m}=\frac{1}{\omega_{\mathrm{o}}^{2}} \frac{1}{C_{\mathrm{p}}+C_{\mathrm{m}} Q^{2} /\left(1+Q^{2}\right)},
$$

where $C_{p}$ models the parasitic capacitance between node $A$ and ground.

To ease the analysis of the proposed rectenna and also gain more insight into its performance, a compact Thévenin model is provided here. First, the left-hand equivalent circuit of Figure 3 accounts for the antenna, the matching network, and the parasitic elements $\left(R_{\mathrm{p}}-C_{\mathrm{p}}\right)$ of the coil, diode, and layout of the circuit. These parasitic elements are derived in Appendix A, where $R_{\mathrm{p}}$ models the losses of the coil and diode and $C_{\mathrm{p}}$ includes the parasitic capacitance of the diode, coil, and layout.

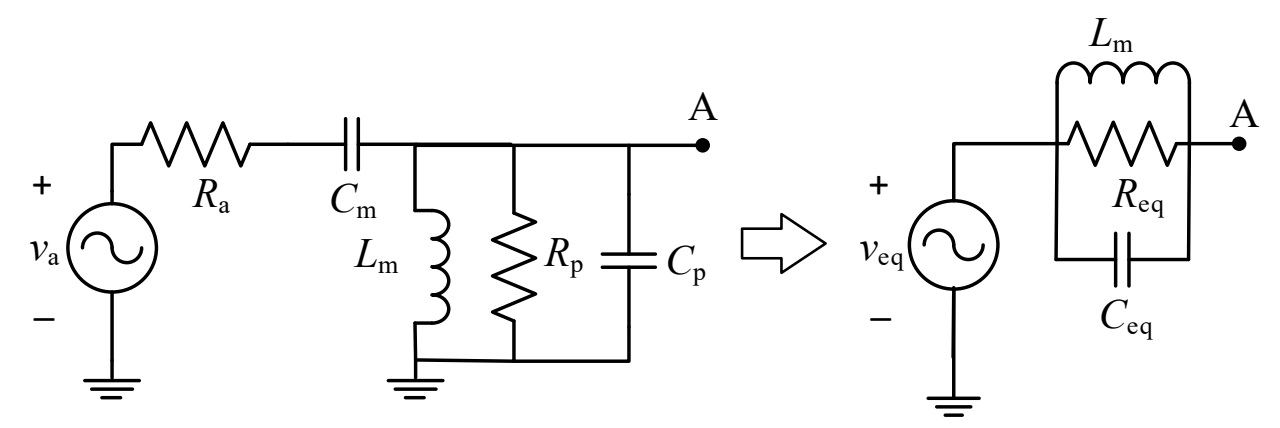

Figure 3. (left) Equivalent input circuit of the antenna and L-matching network considering the parasitic effects of the coil and diode and (right) its Thévenin equivalent circuit.

Analyzing the left-hand circuit of Figure 3 at $f_{\mathrm{o}}$, we can achieve the Thévenin equivalent represented by the right-hand circuit of Figure 3, where:

$$
\begin{gathered}
v_{\mathrm{eq}}=2 \mathrm{G}_{\mathrm{t}} v_{\mathrm{a}} \frac{R_{\mathrm{p}}}{4 G_{\mathrm{t}}^{2} R_{\mathrm{a}}+R_{\mathrm{p}}}, \\
R_{\mathrm{eq}}=\left(4 G_{\mathrm{t}}^{2} R_{\mathrm{a}}\right) \| R_{\mathrm{p}}, \\
C_{\mathrm{eq}}=C_{\mathrm{m}} \frac{Q^{2}}{1+Q^{2}}+C_{\mathrm{p}} .
\end{gathered}
$$

Next, the Thévenin equivalent of Figure 3 is linked to the next stage of the rectenna, the rectifier, resulting in the left-hand circuit of Figure 4, where the diode does not include its parasitic elements since they have been already considered in the previous derivation (they are included in $R_{\mathrm{eq}}$ and $C_{\mathrm{eq}}$ ). The diode is forward biased when $v_{\text {in }}$, assumed sinusoidal, surpasses $V_{\mathrm{o}}$. As a result, $i_{\mathrm{d}}$ is pulsed and is composed of the fundamental frequency $\left(f_{\mathrm{o}}\right)$ as well as its harmonics and a DC component $\left(I_{\mathrm{o}}\right)$. Impedance $Z_{\mathrm{s}}$ (defined in the circuit) is zero at DC (due to the coil $L_{\mathrm{m}}$ ) and is equal to $R_{\mathrm{eq}}$ at $f_{\mathrm{o}}$ since $L_{\mathrm{m}}$ and $C_{\mathrm{eq}}$ form a parallel resonant circuit presenting an infinite impedance. On the other hand, at the harmonics of $f_{\mathrm{o}}$ we have $Z_{\mathrm{s}}<<R_{\mathrm{eq}}$ (due to $C_{\mathrm{eq}}$ ) whenever $Q$ is high enough. Therefore, only the current at $f_{\mathrm{o}}\left(i_{\text {in }}\right)$ originates a voltage drop and $v_{\text {in }}$ will be sinusoidal, as assumed before. Thus, apart 
from boosting the voltage, the matching network ideally acts as an input band-pass filter that prevents any of the DC current and harmonics to flow through the antenna resistance and dissipate power. This leads to an ideal rectenna efficiency of $100 \%$, assuming no losses in the circuit components and in the diode [34]. Contrariwise, when no matching network is present, maximum rectenna efficiency decreases to $46 \%$, due to the additional losses at $R_{\mathrm{a}}$ originated by the current harmonics generated by the diode pulsed current, as demonstrated in [35]. Appendix B confirms these results via simulations. Finally, the value of $C_{\mathrm{o}}$ has to be much higher than the diode junction capacitance $\left(C_{\mathrm{j}}\right)$, as explained in Appendix A, to keep $V_{\mathrm{o}}$ nearly constant, that is, with a low voltage ripple $\left(\Delta V_{\mathrm{o}}\right)$. This second condition leads to:

$$
C_{\mathrm{o}}>\frac{I_{\mathrm{o}}}{\Delta V_{\mathrm{o}} f_{\mathrm{o}}} .
$$

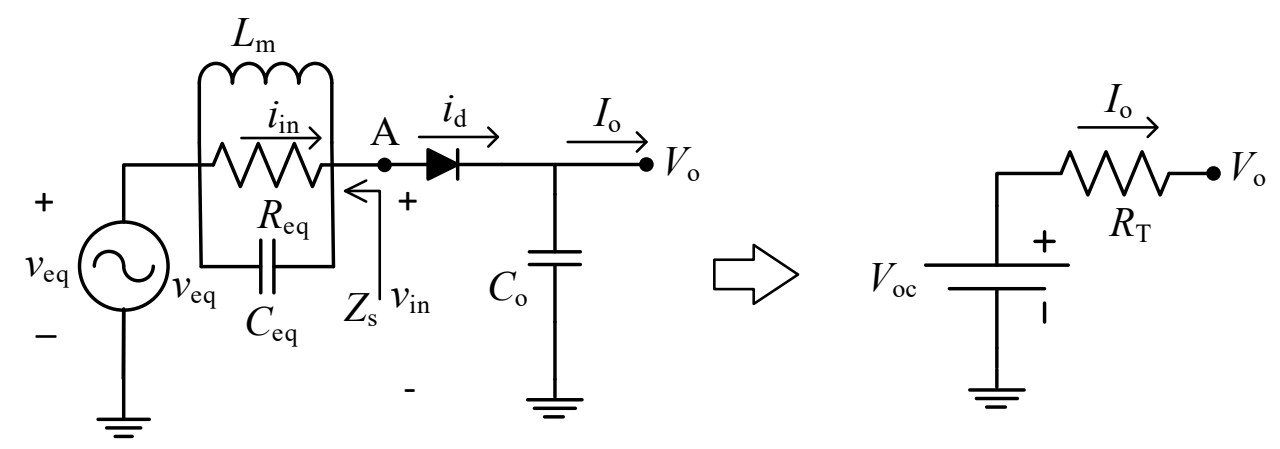

Figure 4. (left) Equivalent circuit of the rectenna using the right-hand circuit of Figure 3 and (right) its Thévenin equivalent.

The left-hand circuit of Figure 4 leads to the equivalent Thévenin circuit of the rectenna, represented by the right-hand circuit of Figure 4, by linking their output voltage-current relationship. For the left-hand circuit, we have:

$$
V_{\mathrm{o}}=V_{\mathrm{inp}}-V_{\gamma}
$$

assuming a fixed forward voltage drop $V_{\gamma}$ at the diode and:

$$
V_{\text {inp }}=V_{\text {eqp }}-R_{\text {eq }} I_{\text {inp }}
$$

where $V_{\text {eqp }}$ and $I_{\text {inp }}$ are the amplitudes of $v_{\text {eq }}$ and $i_{\text {in }}$, respectively. Substituting (8) into (7) provides:

$$
V_{\mathrm{o}}=V_{\mathrm{eqp}}-V_{\gamma}-R_{\mathrm{eq}} I_{\mathrm{inp}}
$$

On the other hand, for the right-hand circuit we have:

$$
V_{\mathrm{o}}=V_{\mathrm{oc}}-R_{\mathrm{T}} I_{\mathrm{o}}
$$

Then, by equating powers, we obtain:

$$
P_{\text {in }}=P_{\mathrm{o}}+P_{\mathrm{d}}
$$

where

$$
\begin{gathered}
P_{\text {in }}=\frac{V_{\text {inp }} I_{\text {inp }}}{2}, \\
P_{\mathrm{O}}=V_{\mathrm{o}} I_{\mathrm{O}}, \\
P_{\mathrm{d}}=V_{\gamma} I_{\mathrm{O}},
\end{gathered}
$$

and $P_{\mathrm{d}}$ is the average power dissipated across the diode. Thus, replacing (12) into (11) and using (7), we arrive at the following:

$$
I_{\text {inp }}=2 I_{\mathrm{o}}
$$


Finally, using (13) in (9) and equating (9) and (10), we obtain the parameters of the Thévenin model:

$$
\begin{gathered}
V_{\mathrm{oc}}=V_{\text {eqp }}-V_{\gamma}, \\
R_{\mathrm{T}}=2 R_{\mathrm{eq}}
\end{gathered}
$$

where $V_{\text {eqp }}$ can be derived from $v_{\text {eq }}$ in (5), using $V_{\text {ap }}$ instead of $v_{\mathrm{a}}$, resulting in:

$$
V_{\text {eqp }}=2 \mathrm{G}_{\mathrm{t}} V_{\mathrm{ap}} \frac{R_{\mathrm{p}}}{4 \mathrm{G}_{\mathrm{t}}^{2} R_{\mathrm{a}}+R_{\mathrm{p}}} .
$$

Then, using (15) and $R_{\mathrm{eq}}$ of (5) in (14), we have:

$$
\begin{gathered}
V_{\mathrm{oc}}=2 G_{\mathrm{t}} V_{\mathrm{ap}} \frac{R_{\mathrm{p}}}{4 G_{\mathrm{t}}^{2} R_{\mathrm{a}}+R_{\mathrm{p}}}-V_{\gamma}, \\
R_{\mathrm{T}}=2\left[\left(4 G_{\mathrm{t}}^{2} R_{\mathrm{a}}\right) \| R_{\mathrm{p}}\right] .
\end{gathered}
$$

Therefore, from (16), with an increasing $P_{\mathrm{av}}$ and thus $V_{\mathrm{ap}}, V_{\mathrm{oc}}$ increases whereas $R_{\mathrm{T}}$ holds constant. Next, from (10), we can express $I_{\mathrm{o}}$ as:

$$
I_{\mathrm{o}}=\left(V_{\mathrm{oc}}-V_{\mathrm{o}}\right) / R_{\mathrm{T}},
$$

and the output power $P_{\mathrm{o}}$ over a load resistor $R_{\mathrm{o}}$ can be simply calculated as:

$$
P_{\mathrm{o}}=V_{\mathrm{o}} I_{\mathrm{o}}=\frac{V_{\mathrm{oc}} V_{\mathrm{o}}-V_{\mathrm{o}}^{2}}{R_{\mathrm{T}}},
$$

being the power efficiency of the rectenna as:

$$
\eta_{\text {rect }}=\frac{P_{\mathrm{o}}}{P_{\mathrm{av}}}=\frac{V_{\mathrm{oc}} V_{\mathrm{o}}-V_{\mathrm{o}}^{2}}{P_{\mathrm{av}} R_{\mathrm{T}}} .
$$

Applying the maximum power transfer theorem, maximum power is extracted from the rectenna for $V_{\mathrm{o}}=0.5 V_{\mathrm{oc}}$, which is known as the maximum power point (MPP) voltage $\left(V_{\mathrm{MPP}}\right)$. From (19), the resulting efficiency is as:

$$
\eta_{\text {rect,max }}=\frac{V_{\mathrm{oc}}^{2}}{4 P_{\mathrm{av}} R_{\mathrm{T}}} .
$$

Thus, using (16) in (20), we arrive at:

$$
\eta_{\text {rect, } \max }=\frac{R_{\mathrm{p}}}{4 G_{\mathrm{t}}^{2} R_{\mathrm{a}}+R_{\mathrm{p}}}\left(1-\frac{V_{\gamma}}{\sqrt{2 R_{\mathrm{a}} P_{\mathrm{av}}}} \frac{4 G_{\mathrm{t}}^{2} R_{\mathrm{a}}+R_{\mathrm{p}}}{4 G_{\mathrm{t}} R_{\mathrm{p}}}\right)^{2} .
$$

As can be seen from (21), $\eta_{\mathrm{rect}, \max }$ increases with increasing $P_{\mathrm{av}}$. Obviously, with no losses $\left(R_{\mathrm{p}}=\infty\right.$ and $\left.V_{\gamma}=0\right) \eta_{\text {rect,max }}=1$ is obtained. On the other hand, the dependence of $\eta_{\text {rect,max }}$ on $G_{t}$ is rather more complex. In [33], an optimum value of $G_{t}$ was derived arising from the trade-off between the losses introduced by the coil and that due to the voltage drop of the diode. This optimum gain leads, from (16), to a particular value of $R_{\mathrm{T}}$.

\section{MPPT and Sensor Node}

In general, a sensor node directly connected to the output of the rectenna will not provide an equivalent resistance $R_{\mathrm{o}}=R_{\mathrm{T}}$, at which the rectenna output operates at the MPP. Thus, an impedance matching stage (in addition to the matching network of the rectenna) is needed between the rectenna output and the sensor node, which can be implemented by a DC/DC converter. An MPPT, which consists of a DC/DC converter plus a tracking algorithm, can be used for automatically searching and 
settling that optimum value of $R_{\mathrm{O}}$, which also corresponds to $V_{\mathrm{O}}=V_{\mathrm{MPP}}$. Thus, the overall power efficiency of the RF harvester will be given by the following:

$$
\eta_{\mathrm{T}}=\eta_{\mathrm{rect}, \max } \eta_{\mathrm{MPPT}}
$$

where $\eta_{\text {MPPT }}$ is the efficiency of the MPPT and $\eta_{\text {rect }}=\eta_{\text {rect,max }}$ since the MPPT biases the rectenna at the MPP.

In this work, the fractional open circuit voltage (FOCV) MPPT technique is used, since it leads to simple and power efficient implementations. In this technique, the open circuit voltage $\left(V_{\text {oc }}\right)$ of the energy transducer (a rectenna here) is first measured and a fraction $k$ of $V_{\mathrm{oc}}$ is used to operate at $V_{\mathrm{MPP}}$ and thus achieve $\eta_{\text {rect,max }}$. Taking into account the analysis in Section 2, a proper choice here is $k=0.5$ $\left(V_{\mathrm{o}}=V_{\mathrm{MPP}}=0.5 V_{\mathrm{oc}}\right)$.

Figure 5 presents the block diagram for the implementation of the FOCV MPPT technique, where $C_{\mathrm{L}}, C_{\mathrm{REF}}$, and $C_{\text {load }}$ are capacitors, $R_{\mathrm{oc} 1}$ and $R_{\mathrm{oc} 2}$ are resistors, $S_{1}$ and $S_{2}$ are switches, $V_{\text {load }}$ is the output voltage used to power the sensor node, and $P_{\text {load }}$ is the power transferred to the sensor node. The operation is the following. First, $\mathrm{S}_{1}$ closes and $\mathrm{S}_{2}$ opens (sampling period). For high values of $R_{\mathrm{oc} 1}$ and $R_{\mathrm{oc} 2}$, the output of the rectenna can be considered as open and thus $V_{\mathrm{O}}=V_{\mathrm{oc}}$. The voltage divider formed by $R_{\mathrm{oc} 1}$ and $R_{\mathrm{oc} 2}$ fixes $V_{\mathrm{MPP}}=k V_{\mathrm{oc}}$, being $k=0.5$ here (i.e., $R_{\mathrm{oc} 1}=R_{\mathrm{oc} 2}$ ). The input capacitor $\left(C_{\mathrm{L}}\right)$ momentarily stores the incoming harvested energy. Secondly, $\mathrm{S}_{1}$ opens and $\mathrm{S}_{2}$ closes (regulation period). Thus, $\mathrm{V}_{\mathrm{MPP}}$ holds constant thanks to $C_{\mathrm{REF}}$, and the DC/DC converter settles $V_{\mathrm{o}}$ around $V_{\mathrm{MPP}}$ and transfers the harvested energy by the rectenna to the sensor node.

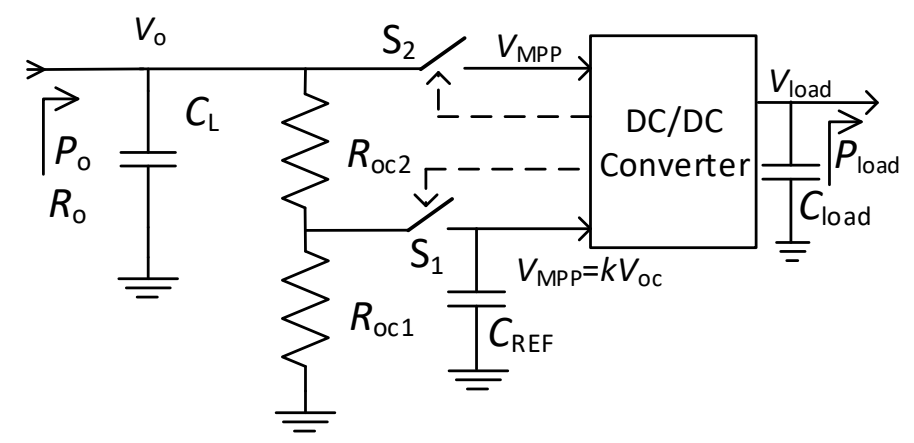

Figure 5. Block diagram for the implementation of the fractional open circuit voltage maximum power point tracking technique.

In order to periodically update $V_{\mathrm{oc}}$ (i.e., a change in $P_{\mathrm{av}}$ changes $V_{\mathrm{oc}}$ ), the described sequence is periodically repeated, with the sampling period being much shorter than the regulation period. In this way, $V_{\mathrm{o}}$ will settle most of time at $V_{\mathrm{MPP}}$. To increase the efficiency at light loads, the DC/DC converter uses special control techniques such as pulse frequency modulation (PFM) or burst-mode [36].

Taking into account (22), $P_{\text {load }}$ can be related with $P_{\text {av }}$ as follows:

$$
P_{\text {load }}=\eta_{\mathrm{T}} P_{\mathrm{av}}
$$

The value of $P_{\text {load }}$ and thus of $P_{\text {av }}$ must be enough, in average, to power the sensor node, which usually includes a rechargeable storage unit. This unit accounts for the variability of $P_{\mathrm{av}}$, gathering or providing energy whenever $P_{\text {av }}$ is higher or lower than required. Storage units can be supercapacitors, batteries, or a combination of both [37]. On the other hand, the required value of $P_{\text {load }}$ and thus of $P_{\text {av }}$ can be reduced by operating the sensor node in sleep mode most of the time and minimizing its active time. 


\section{Materials and Methods}

The rectenna shown in Figure 2 was implemented on a printed circuit board with Rogers substrate and with the following components: $C_{\mathrm{m}}=0.5 \mathrm{pF}$ (AVX, Fountain Inn, SC, USA), $L_{\mathrm{m}}=27 \mathrm{nH}$ (0603CS model, Coilcraft, Cary, IL, USA), $C_{o}=1 \mathrm{nF}$, and a Schottky HSMS-2850 diode (Avago Technologies, San Jose, CA, USA) [33]. The selected value of $C_{0}$ comfortably accomplished, in order to theoretically have a small ripple (below $1 \mathrm{mV}$ ) with the values of $I_{\mathrm{O}}$ shown later in Section 5 , as well as the condition stated in Appendix $A\left(C_{\mathrm{o}}>C_{\mathrm{j}}\right)$. The circuit of Figure 2 was used for the rectenna characterization, where an RF generator (Agilent E4433B, Santa Clara, CA, USA) was connected at the input instead of the antenna and a Source Measure Unit (SMU, Agilent B2901A, Santa Clara, CA, USA) configured as a voltage sink (quadrant IV) at the output. The generator was set at a tuned optimal frequency of $808 \mathrm{MHz}$ and at different values of $P_{\mathrm{av}}(-30 \mathrm{dBm},-20 \mathrm{dBm}$, and $-10 \mathrm{dBm})$. For each value of $P_{\mathrm{av}}$, the SMU was set at different values of $V_{\mathrm{o}}$ while measuring $P_{\mathrm{o}}$. Then, $\eta_{\text {rect }}$ was obtained as $P_{\mathrm{o}} / P_{\mathrm{av}}$.

As for the FOCV MPPT, a BQ25504 chip (Texas Instruments, Dallas, TX, USA) was used, and in particular an evaluation board provided by the manufacturer. The chip contains a boost converter with PFM control and the board includes, in reference to Figure 5, $C_{\mathrm{L}}=4.8 \mu \mathrm{F}$ (combination of two ceramic capacitors of $4.7 \mu \mathrm{F}$ and $100 \mathrm{nF}$ placed in parallel), $C_{\mathrm{REF}}=10 \mathrm{nF}$, and $C_{\text {load }}=104.8 \mu \mathrm{F}$ (combination of three ceramic capacitors of $100 \mu \mathrm{F}, 4.7 \mu \mathrm{F}$, and $100 \mathrm{nF}$ placed in parallel). The default values of $R_{\mathrm{oc} 1}$ and $R_{\mathrm{oc} 2}$ were modified to $10 \mathrm{M} \Omega$ in order to fix $k=0.5$ (the default value is set to 0.78 ). The sampling and regulation periods are prefixed by the chip to $256 \mathrm{~ms}$ and $16 \mathrm{~s}$, respectively. Then, the efficiency of the whole RF harvester (rectenna plus MPPT) was characterized by using the RF generator at the input of the rectenna and the SMU set at $3 \mathrm{~V}$ at the output of the MPPT ( $\left.V_{\text {load }}\right)$. The RF generator was set at different values of $P_{\mathrm{av}}$, from $-20 \mathrm{dBm}$ to $-5 \mathrm{dBm}$ in steps of $1 \mathrm{dBm}$, and for each value the SMU measured the output power $P_{\text {load }}$. Then, from (23), $\eta_{\mathrm{T}}$ was estimated.

For demonstration purposes, the RF harvester including the MPPT was also employed to power a sensor node intended to upgrade a mechanical gas meter to a smart device [38]. For these tests, the node was programmed to stay in a standby mode, consuming $1.4 \mu \mathrm{A}$. The input power $\left(P_{\text {av }}\right)$ was set to keep the voltage supply of the sensor node $\left(V_{\text {load }}\right)$ at $3 \mathrm{~V}$, thus $P_{\text {load }}=4.2 \mu \mathrm{W}$. As for the RF harvester input, two configurations were used: (1) an RF generator and (2) a receiving monopole antenna. In the second case, another identical monopole antenna was connected to a nearby RF generator, jointly acting as a wireless energy transmitter. The antennas showed an insertion loss higher than $10 \mathrm{~dB}$ at $808 \mathrm{MHz}$. Figure 6 shows pictures of both setups.
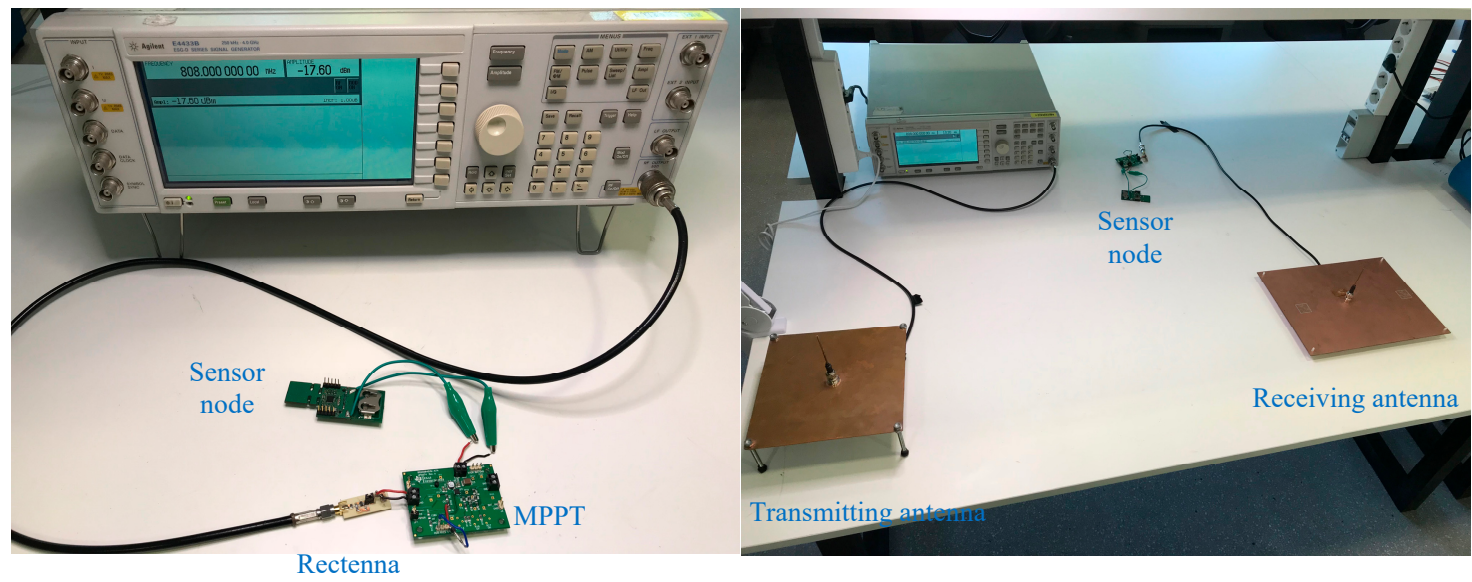

Figure 6. Picture of the setups for powering the sensor node using, for the RF harvester input, (left) the RF generator or (right) a monopole antenna. 


\section{Experimental Results and Discussion}

As for the proposed rectenna, Figure 7 shows the measured values (in dots) of $I_{\mathrm{o}}$ (blue circles) and $\eta_{\text {rect }}$ (red squares) as a function of $V_{\mathrm{o}}$ at different values of $P_{\mathrm{av}}$. A least-squares fitting of (17) to the experimental data of $I_{\mathrm{O}}$ was performed (blue continuous line) to obtain the Thévenin parameters $\left(V_{\mathrm{oc}}\right.$ and $R_{\mathrm{T}}$ ) at each power level, which are shown in Table 1. Calculated values of $V_{\mathrm{ap}}$, from (1), and of $V_{\text {eqp }}$, from (15), are also included in Table 1. This fitting differs from that performed in [32], where the efficiency data $\left(\eta_{\text {rect }}\right)$ were used instead, which leads to slight differences in the Thévenin parameters. The new fitting procedure was considered more convenient as both $V_{\mathrm{oc}}$ and $R_{\mathrm{T}}$ can be more easily inferred from the fitting curve. As can be seen, the fitting curves match well the experimental data, and more at the highest power of $-10 \mathrm{dBm}$, which confirms that the rectenna can be well approximated by a Thévenin equivalent circuit. Then, $V_{\mathrm{oc}}$ and $R_{\mathrm{T}}$ were used to obtain $\eta_{\text {rect }}$ using (19), and the resulting curves are also represented in Figure 7 (red continuous line). The match with the experimental data is good, and again better at $-10 \mathrm{dBm}$.

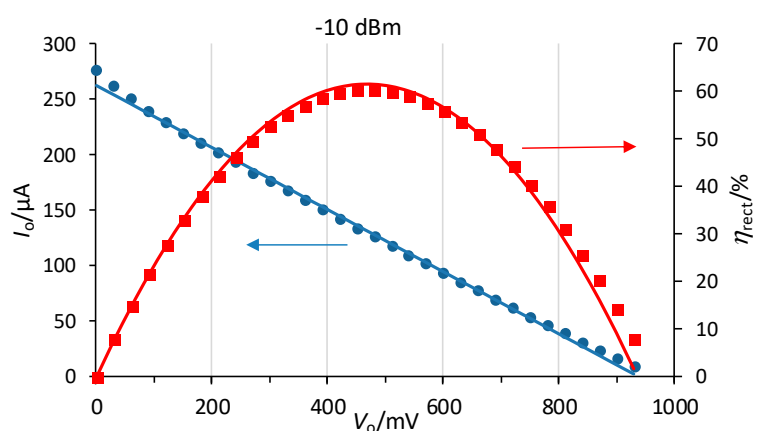

(a)

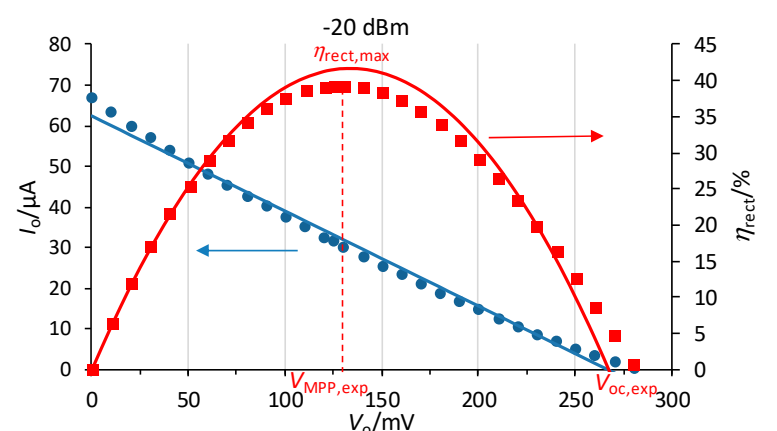

(b)

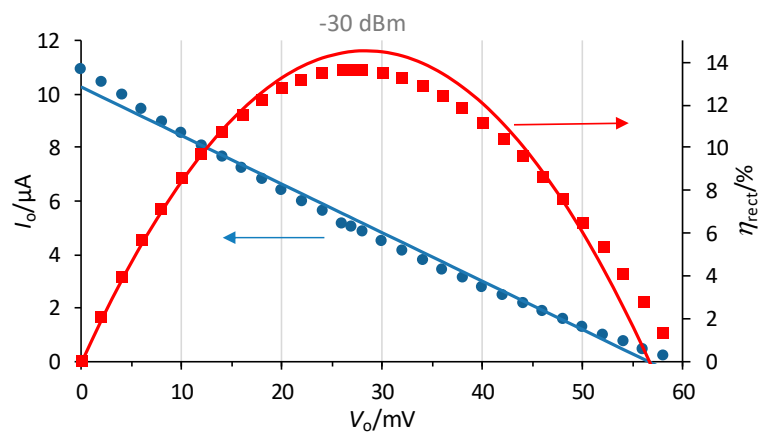

(c)

Figure 7. Measured values (dots) and least-squares fittings (continuous lines) of $I_{\mathrm{o}}$ and $\eta_{\text {rect }}$ versus $V_{\mathrm{o}}$ for the rectenna at $P_{\mathrm{av}}$ equal to (a) $-10 \mathrm{dBm},(\mathbf{b})-20 \mathrm{dBm}$, and (c) $-30 \mathrm{dBm}$.

Table 1. Inferred values of $V_{\mathrm{oc}}$ and $R_{\mathrm{T}}$ and calculated values of $V_{\mathrm{eqp}}$ at different values of $P_{\mathrm{av}}$.

\begin{tabular}{ccccc}
\hline $\boldsymbol{P}_{\text {av }}(\mathbf{d B m})$ & $\boldsymbol{V}_{\text {ap }}(\mathbf{m V})$ & $\boldsymbol{V}_{\mathbf{~ o c}}(\mathbf{m V})$ & $\boldsymbol{R}_{\mathrm{T}}(\mathbf{k} \Omega)$ & $\boldsymbol{V}_{\text {eqp }}(\mathbf{m V})$ \\
\hline-10 & $200 \mathrm{mV}$ & 937 & 3.56 & 1183 \\
\hline-20 & $63.2 \mathrm{mV}$ & 268 & 4.29 & 374 \\
\hline-30 & $20.0 \mathrm{mV}$ & 56.6 & 5.51 & 118.3 \\
\hline
\end{tabular}

With $C_{\mathrm{m}}=0.5 \mathrm{pF}, R_{\mathrm{a}}=50 \Omega$, and $f_{\mathrm{o}}=808 \mathrm{MHz}, Q=7.88$ results from (3), and $G_{\mathrm{t}}=3.97$ from (2). Then, from (16) and assuming the value of $R_{\mathrm{p}}=9.21 \mathrm{k} \Omega$ derived in Appendix $\mathrm{A}, R_{\mathrm{T}}=4.7 \mathrm{k} \Omega$ is obtained, which is within the range of values found in Table 1 . The inferred values of $R_{\mathrm{T}}$ moderately change with $P_{\mathrm{av}}$ due to the relative low value of $Q$, which limits the accuracy of the rectenna model proposed in Section 2. However, a higher value of $Q$, which could be obtained using a lower value of $C_{m}$ and appropriately readjusting $L_{m}$, does not lead to the optimum gain $G_{t}$ [33], thus decreasing 
the power efficiency. On the other hand, $V_{\mathrm{oc}}$ in Table 1 increases with increasing $P_{\mathrm{av}}$ and thus $V_{\mathrm{ap}}$, which agrees with (16). The values of $V_{\mathrm{oc}}$ can be estimated in advance, when necessary, from (16) by calculating $V_{\text {eqp }}$ from (15), shown in Table 1, and inferring a value of $V_{\gamma}$ from the manufacturer data or from simulations.

From the measured data of $\eta_{\text {rect }}$ (red squares in Figure 7), Table 2 shows the achieved $\eta_{\text {rect,max }}$ and its corresponding voltage $\left(V_{\mathrm{MPP}, \exp }\right)$, as well as the experimental open circuit voltage $\left(V_{\text {oc,exp }}\right)$ of the rectenna. In Figure $7, \eta_{\text {rect,max }}, V_{\mathrm{MPP}, \text { exp }}$, and $V_{\text {oc,exp }}$ are also marked for $P_{\mathrm{av}}=-20 \mathrm{dBm}$. As can be seen, $\eta_{\text {rect,max }}$ increases with increasing $P_{\mathrm{av}}$, ranging from $13.6 \%$ at $-30 \mathrm{dBm}$ to $60.3 \%$ at $-10 \mathrm{dBm}$, which agrees with (21). The values of $\eta_{\text {rect,max }}$ can be estimated in advance, when necessary, from (21) and inferring a value of $V_{\gamma}$ from the manufacturer data or from simulations. One particular case is the upper limit, which would be achieved for $P_{\text {av }} \rightarrow \infty$ (or $V_{\gamma} \rightarrow 0$ ), in our case $74 \%$. The resulting efficiencies $\left(\eta_{\text {rect,max }}\right)$ are among the highest published in the literature for similar designs [33]. On the

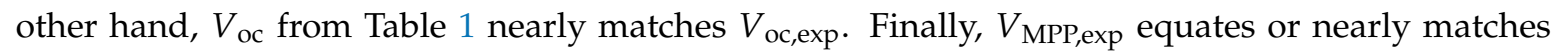
$0.5 V_{\mathrm{oc}, \text { exp }}$, the regulated voltage at the input of the MPPT. Thus, the proposed and implemented MPPT will be able to extract the maximum power (or nearly) from the rectenna.

Table 2. Experimental values of $\eta_{\mathrm{rect,max}}, V_{\mathrm{MPP}, \text { exp }}$, and $V_{\mathrm{oc}, \text { exp }}$ at different values of $P_{\mathrm{av}}$.

\begin{tabular}{cccc}
\hline $\boldsymbol{P}_{\text {av }}(\mathbf{d B m})$ & $\eta_{\text {rect,max }}(\%)$ & $\boldsymbol{V}_{\mathbf{M P P , e x p}}(\mathbf{m V})$ & $\boldsymbol{V}_{\text {oc,exp }}(\mathbf{m V})$ \\
\hline-10 & 60.3 & 480 & 960 \\
\hline-20 & 39.3 & 130 & 280 \\
\hline-30 & 13.6 & 27 & 60 \\
\hline
\end{tabular}

As for the whole RF harvester (rectenna plus the MPPT), Figure 8 shows the experimental values of $\eta_{\mathrm{T}}$ versus $P_{\mathrm{av}}$. At $-20 \mathrm{dBm}, \eta_{\text {rect,max }}=39.3 \%$ (Table 2) but $\eta_{\mathrm{T}}=6.5 \%$, resulting, from (22), in $\eta_{\text {MPPT }}=16.5 \%$. This low value of $\eta_{\text {MPPT }}$ is due to both a low input voltage value $\left(140 \mathrm{mV}=0.5 V_{\text {oc,exp }}\right)$ and a low value of $P_{\mathrm{o}}\left(3.9 \mu \mathrm{W}=\eta_{\mathrm{rect}, \max } P_{\mathrm{av}}\right)$. Contrariwise, at $-10 \mathrm{dBm}, \eta_{\text {rect,max }}=60.3 \%$ and $\eta_{\mathrm{T}}=48.6 \%$, resulting in $\eta_{\mathrm{MPPT}}=80.6 \%$, which agrees with the data from the BQ25504 chip's datasheet. At higher values of $P_{\mathrm{av}}(-5 \mathrm{dBm}), \eta_{\mathrm{T}}$ reached a value of $55.6 \%$. Compared to [6], where a similar chip for the MPPT was used, $\eta_{\mathrm{T}}$ is quite higher.

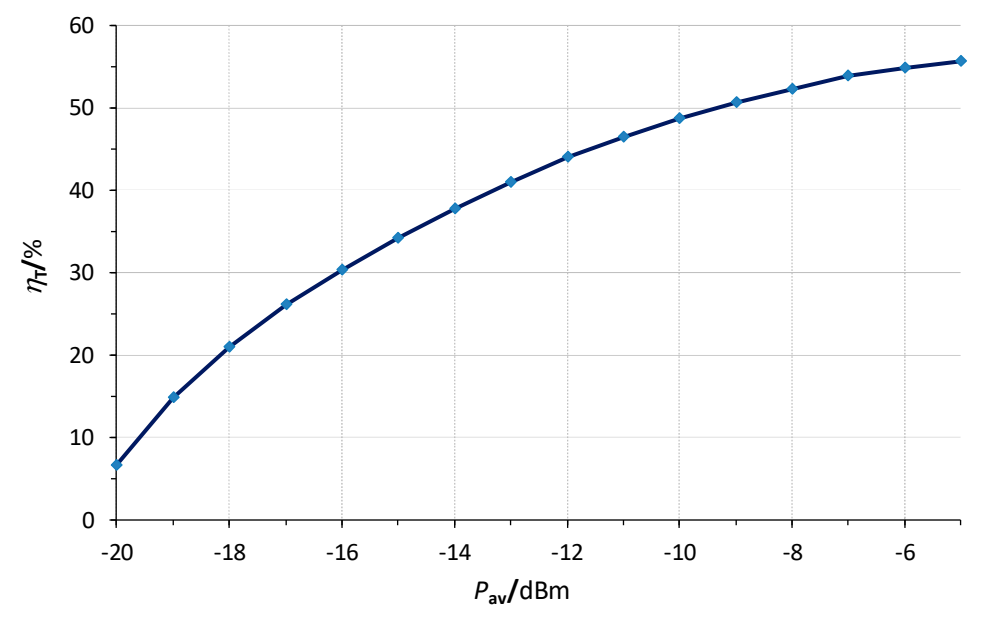

Figure 8. Overall efficiency $\left(\eta_{\mathrm{T}}\right)$ of the RF harvester.

When powering the sensor node, the required value of $P_{\mathrm{av}}$ was $-17.6 \mathrm{dBm}$. This value fits well with (23), considering the corresponding efficiency in Figure $8(\approx 24 \%)$. This performance was also tested with the antennas at a distance of 0.5 and $1 \mathrm{~m}$. The power output of the remote RF generator was tuned at appropriate values so as to operate the node, resulting in 8.0 and $13.2 \mathrm{dBm}$, respectively. These values accounted for the respective link budgets. 


\section{Conclusions}

This work proposed a compact Thévenin model for a rectenna and its application for designing a high-efficiency RF harvester. The rectenna under study consists of an L-matching network and a half-wave rectifier. Explicit expressions for the Thévenin voltage and resistance were derived that offer insight into the operation of the rectenna. An expression was also provided for the power efficiency. The rectenna was implemented and characterized from -30 to $-10 \mathrm{dBm}$ at $808 \mathrm{MHz}$ and the results mainly agreed with the derived model, with differences arising from the limited $Q$ factor of the matching network. High efficiencies were obtained, in particular $60 \%$ at $-10 \mathrm{dBm}$. Then, an ensuing MPPT was also added, where the behavior of the rectenna as an equivalent Thévenin circuit allowed the use of a simple FOCV technique. The whole RF harvester (rectenna plus MPPT) showed an overall efficiency near $50 \%$ at $-10 \mathrm{dBm}$. Further tests were performed with a nearby transmitting antenna for powering a sensor node with a power consumption of $4.2 \mu \mathrm{W}$.

Author Contributions: Conceptualization, M.G.; Formal analysis, M.G. and F.R.; Funding acquisition, M.G. and F.R.; Investigation, M.G. and E.R.-V.; Methodology, M.G.; Project administration, M.G. and F.R.; Writing-original draft, M.G.; Writing-review and editing, M.G. and F.R.

Funding: This work was supported by the Secretariat of University and Research of the Ministry of Business and Knowledge of the Government of Catalonia, by the Spanish State Research Agency (AEI) and by the European Regional Development Fund under Project TEC2016-76991-P.

Acknowledgments: The authors wish to thank Josep Jordana, Francesc-Josep Robert, and Jordi Berenguer for their initial support, and the Castelldefels School of Telecommunications and Aerospace Engineering, Barcelona, Spain, for the RF instrumentation needed to perform the experiments.

Conflicts of Interest: The authors declare no conflict of interest.

\section{Appendix A. Parallel Circuit Model of the Inductor and Diode}

The use of a matching network leads to sinusoidal voltage and current waveforms at $f_{\mathrm{o}}$, as mentioned in Section 2. Here, the equivalent circuit model at $f_{\mathrm{o}}$ is derived from the manufacturer models of the diode (https: / / docs.broadcom.com/docs/AV02-1377EN) and inductor (https:/ / www. coilcraft.com/pdfs/spice_0603cs.pdf) used for the implemented rectenna and reported in Section 4. This model will be used in the left-hand circuit of Figure 3.

First, the left-hand circuit in Figure A1 shows the equivalent linear circuit model of the diode, connected between node $\mathrm{A}$ and the $V_{\mathrm{o}}$ node at Figure 2, together with the output capacitor $C_{\mathrm{o}}$, where $R_{\mathrm{s}}$ is the parasitic series resistance, $C_{\mathrm{j}}$ is the parasitic junction capacitance, and $R_{\mathrm{j}}$ is the junction resistance. $R_{\mathrm{j}}$ depends inversely on the bias current and makes only sense for modelling small current variations around a bias current. In our case, the diode current is pulsed and thus the inclusion of $R_{\mathrm{j}}$ is not appropriate. Instead, a constant voltage drop will be assumed in Section 2 for the analysis of the circuit of Figure 4.
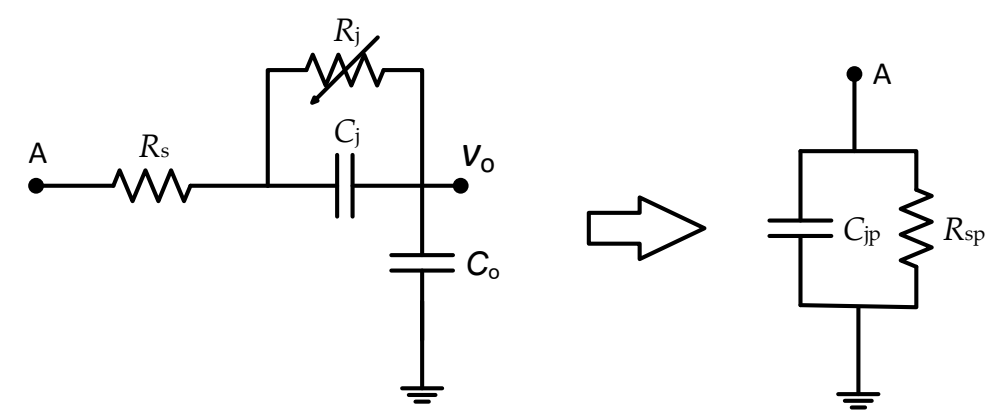

Figure A1. Equivalent linear circuit model of the HSMS-2850 diode together with (left) the output capacitor $C_{o}$ and (right) its parallel equivalent circuit. 
Using the series-to-parallel equivalent circuit transformation for the left-hand circuit of Figure A1 without $R_{\mathrm{j}}$ and considering $C_{\mathrm{o}} \gg>C_{\mathrm{j}}$, the right-hand circuit results, where:

$$
\begin{gathered}
R_{\mathrm{sp}}=R_{\mathrm{s}} \frac{R_{\mathrm{s}}^{2} C_{\mathrm{j}}^{2} \omega_{\mathrm{o}}^{2}+1}{R_{\mathrm{s}}^{2} C_{\mathrm{j}}^{2} \omega_{\mathrm{o}}^{2}}, \\
C_{\mathrm{jp}}=\frac{C_{\mathrm{j}}}{R_{\mathrm{s}}^{2} C_{\mathrm{j}}^{2} \omega_{\mathrm{o}}^{2}+1} .
\end{gathered}
$$

From the diode datasheet, $R_{\mathrm{s}}=25 \Omega$ and $C_{\mathrm{jo}}=0.18 \mathrm{pF}\left(C_{\mathrm{jo}}\right.$ is $C_{\mathrm{j}}$ at zero bias and will be the assumed value for $C_{\mathrm{j}}$ hereafter). With $f_{\mathrm{o}}=808 \mathrm{MHz}, R_{\mathrm{sp}}=47.9 \mathrm{k} \Omega$ results from $(\mathrm{A} 1)$ and $C_{\mathrm{jp}} \approx C_{\mathrm{j}}=180 \mathrm{fF}$ results from (A2).

As for the inductor, connected between node A and ground at Figure 2, the left-hand circuit of Figure A2 shows the manufacturer model, where $R_{v}=k \sqrt{f_{\mathrm{o}}}$. Using the series-to-parallel circuit transformation, the circuit in the middle is obtained, where:

$$
\begin{gathered}
L_{\mathrm{mp}}=L_{\mathrm{m}}\left[1+\left(\frac{R_{\mathrm{v}}}{\omega_{\mathrm{o}} L_{\mathrm{m}}}\right)^{2}\right] \\
R_{\mathrm{vp}}=R_{\mathrm{v}}\left[1+\left(\frac{\omega_{\mathrm{o}} L_{\mathrm{m}}}{R_{\mathrm{v}}}\right)^{2}\right], \\
R_{1 \mathrm{p}}=R_{1} \frac{R_{1}^{2} C_{1}^{2} \omega_{\mathrm{o}}^{2}+1}{R_{1}^{2} C_{1}^{2} \omega_{\mathrm{o}}^{2}} \\
C_{1 \mathrm{p}}=\frac{C_{1}}{R_{1}^{2} C_{1}^{2} \omega_{\mathrm{o}}^{2}+1} .
\end{gathered}
$$

From the coil datasheet, $R_{1}=17 \Omega, R_{2}=30 \mathrm{~m} \Omega, C_{1}=49 \mathrm{fF}, L_{\mathrm{m}}=27 \mathrm{nH}$, and $k=5.75 \times 10^{-5}$. At $808 \mathrm{MHz}, R_{\mathrm{v}}=1.63 \Omega$ and from (A3) to (A6), $L_{\mathrm{mp}} \approx L_{\mathrm{m}}=27 \mathrm{nH}, R_{\mathrm{vp}}=11.5 \mathrm{k} \Omega, R_{1 \mathrm{p}}=950 \mathrm{k} \Omega$, and $C_{1 \mathrm{p}} \approx C_{1}=49 \mathrm{fF}$. Then, neglecting $R_{2}$, since it is very small, the right-hand circuit of Figure A2 is obtained, where $R_{\mathrm{Lp}}=R_{\mathrm{vp}} \| R_{1 \mathrm{p}}=11.4 \mathrm{k} \Omega$.

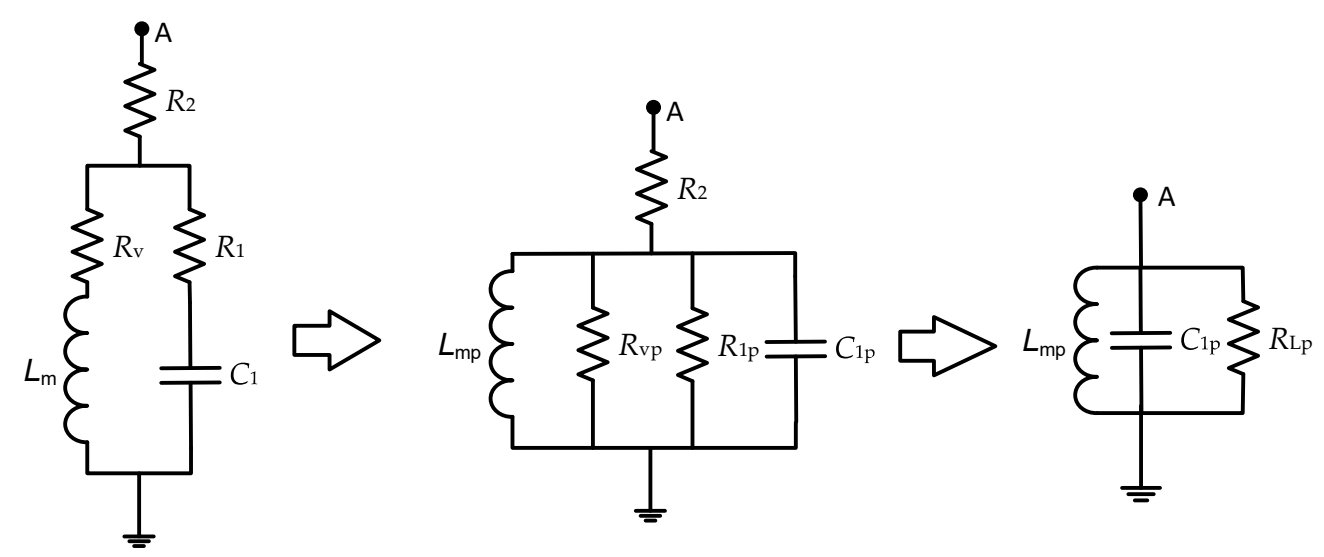

Figure A2. (left) Manufacturer model of the inductor and (middle and right) equivalent circuits.

Joining the right-hand circuits in Figures $\mathrm{A} 1$ and $\mathrm{A} 2$, and considering the parasitic capacitance from node $\mathrm{A}$ to ground arising from the layout $\left(C_{\text {lay }}\right)$, the circuit in Figure $\mathrm{A} 3$ is obtained, where:

$$
\begin{gathered}
R_{\mathrm{p}}=R_{\mathrm{sp}} \| R_{\mathrm{Lp}}=9.21 \mathrm{k} \Omega, \\
C_{\mathrm{p}}=C_{\mathrm{jp}}+C_{1 \mathrm{p}}+C_{\text {lay }} .
\end{gathered}
$$




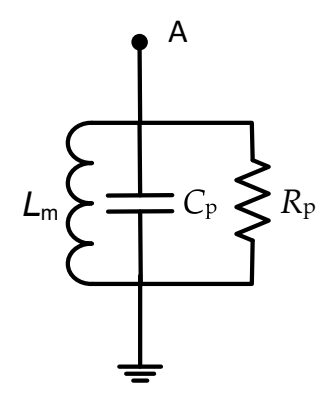

Figure A3. Parallel equivalent circuit of the inductor.

This equivalent circuit is used in the left-hand circuit of Figure 3.

\section{Appendix B. Simulations of the Rectenna Efficiency with and without an L-Matching Network}

In order to highlight the benefits of using a matching network, we report simulation results of the rectenna efficiency with and without an L-matching network. For the simulations, the ADS software (Version 2017, Keysight, Santa Rosa, CA, USA) was used. The simulated circuit with the matching network was that of Figure 2 with a resistor $R_{\mathrm{o}}$ connected at its output, in parallel with $C_{\mathrm{o}}$. Ideal components were used for the matching network with the values reported in Section 4 . The diode was modelled without parasitic elements (null series resistance and junction capacitance) but with a saturation current of $3 \mu \mathrm{A}$ (that corresponding to the HSMS-2850 diode used for the implemented rectenna). For the RF source, a frequency of $808 \mathrm{MHz}$ (that used for the experiments) was used with $P_{\text {av }}$ ranging from -10 to $50 \mathrm{dBm}$ in steps of $20 \mathrm{~dB}$. For the circuit without the matching network, the right terminal of $R_{\mathrm{a}}$ was directly connected to the diode anode (node $\mathrm{A}$ ). For both circuits, a harmonic balance analysis was performed with $P_{\mathrm{av}}$ and $R_{\mathrm{O}}$ as sweeping parameters.

Figure A4 shows the simulation results of the rectenna efficiency $\left(\eta_{\text {rect }}=P_{\mathrm{o}} / P_{\mathrm{av}}\right)$ plotted against $R_{\mathrm{o}}$ for different values of $P_{\mathrm{av}}$. The left graph shows the results for the circuit with the L-matching network. As can be seen, $\eta_{\text {rect }}$ steeply increases for increasing values of $P_{\mathrm{av}}$, achieving around $99 \%$ at $P_{\mathrm{av}}=50 \mathrm{dBm}$. At $-10 \mathrm{dBm}$, efficiency is higher than the corresponding results of Figure 7 because ideal components were used for the simulation. On the other hand, the right graph shows the results for the circuit without the L-matching network. As can be seen, $\eta_{\text {rect }}$ steeply increases for increasing values of $P_{\text {av }}$ but now reaches a maximum value around $46 \%$, as predicted theoretically in [35], due to the additional losses at $R_{\mathrm{a}}$ originated by the current harmonics generated by the diode pulsed current. At $-10 \mathrm{dBm}$, efficiency is lower than $4 \%$. Therefore, the use of the matching network allows a notable increase in the rectenna efficiency, because it provides voltage gain and prevents any of the DC current and harmonics to flow through the antenna resistance.
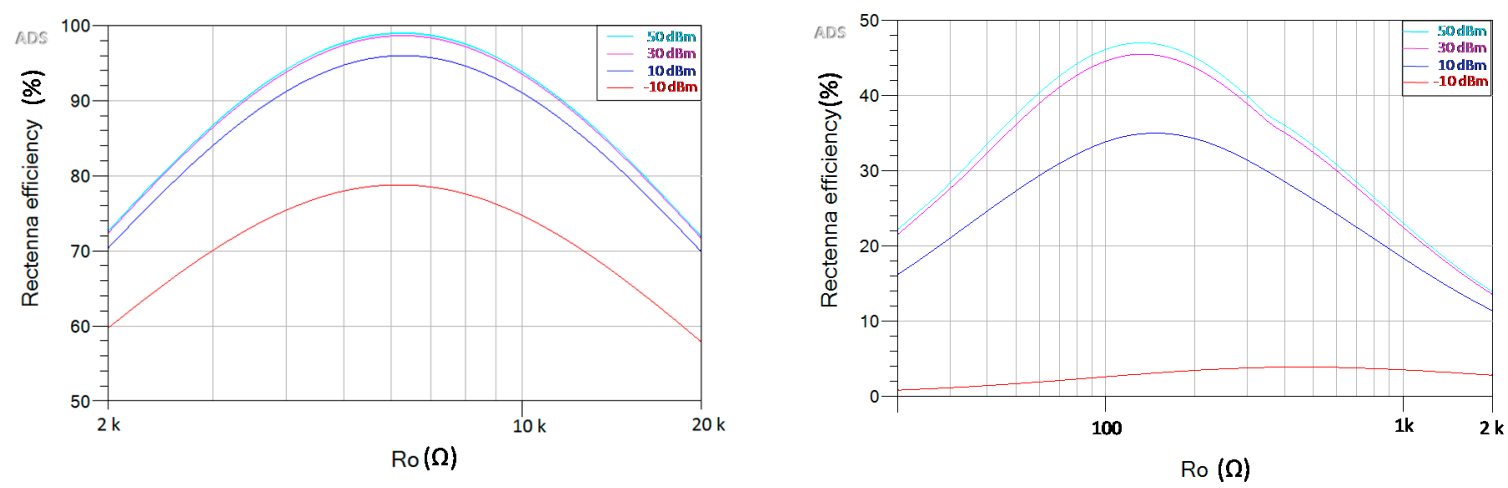

Figure A4. Rectenna efficiency for the circuit (left) with and (right) without the matching network. 


\section{References}

1. Shameli, A.; Safarian, A.; Rofougaran, A.; Rofougaran, M.; De Flaviis, F. Power Harvester Design for Passive UHF RFID Tag Using a Voltage Boosting Technique. IEEE Trans. Microw. Theory Tech. 2007, 55, 1089-1097. [CrossRef]

2. Sample, A.; Smith, J.R. Experimental results with two wireless power transfer systems. In Proceedings of the 2009 IEEE Radio and Wireless Symposium, San Diego, CA, USA, 18-22 January 2009; pp. 16-18.

3. Attaran, A.; Rashidzadeh, R.; Muscedere, R. Chipless RFID tag using RF MEMS switch. Electron. Lett. 2014, 50, 1720-1722. [CrossRef]

4. Álvarez López, Y.; Franssen, J.; Álvarez Narciandi, G.; Pagnozzi, J.; González-Pinto Arrillaga, I.; Las-Heras Andrés, F. RFID Technology for Management and Tracking: E-Health Applications. Sensors 2018, $18,2663$. [CrossRef] [PubMed]

5. Singh, G.; Ponnaganti, R.; Prabhakar, T.V.; Vinoy, K.J. A tuned rectifier for RF energy harvesting from ambient radiations. AEU-Int. J. Electron. Commun. 2013, 67, 564-569. [CrossRef]

6. Talla, V.; Kellogg, B.; Ransford, B.; Naderiparizi, S.; Gollakota, S.; Smith, J.R. Powering the Next Billion Devices with Wi-Fi. In Proceedings of the 11th ACM Conference on Emerging Networking Experiments and Technologies, Heidelberg, Germany, 1-4 December 2015.

7. Piñuela, M.; Mitcheson, P.D.; Lucyszyn, S. Ambient RF energy harvesting in urban and semi-urban environments. IEEE Trans. Microw. Theory Tech. 2013, 61, 2715-2726. [CrossRef]

8. Di Marco, P.; Stornelli, V.; Ferri, G.; Pantoli, L.; Leoni, A. Dual band harvester architecture for autonomous remote sensors. Sens. Actuators A Phys. 2016, 247, 598-603. [CrossRef]

9. Shaker, G.; Chen, R.; Milligan, B.; Qu, T. Ambient electromagnetic energy harvesting system for on-body sensors. Electron. Lett. 2016, 52, 1834-1836. [CrossRef]

10. Stoopman, M.; Keyrouz, S.; Visser, H.J.; Philips, K.; Serdijn, W.A. Co-design of a CMOS rectifier and small loop antenna for highly sensitive RF energy harvesters. IEEE J. Solid-State Circuits 2014, 49, $622-634$. [CrossRef]

11. Soltani, N.; Yuan, F. A High-Gain Power-Matching Technique for Efficient Radio-Frequency Power Harvest of Passive Wireless Microsystems. IEEE Trans. Circuits Syst. I Regul. Pap. 2010, 57, 2685-2695. [CrossRef]

12. Curty, J.-P.; Joehl, N.; Krummenacher, F.; Dehollain, C.; Declercq, M.J. A model for u-power rectifier analysis and design. IEEE Trans. Circuits Syst. I Regul. Pap. 2005, 52, 2771-2779. [CrossRef]

13. Jordana, J.; Reverter, F.; Gasulla, M. Power Efficiency Maximization of an RF Energy Harvester by Fine-tuning an L-matching Network and the Load. Procedia Eng. 2015, 120, 655-658. [CrossRef]

14. Abouzied, M.A.; Ravichandran, K.; Sanchez-Sinencio, E. A Fully Integrated Reconfigurable Self-Startup RF Energy-Harvesting System With Storage Capability. IEEE J. Solid-State Circuits 2017, 52, 704-719. [CrossRef]

15. Nimo, A.; Grgić, D.; Reindl, L.M. Optimization of Passive Low Power Wireless Electromagnetic Energy Harvesters. Sensors 2012, 12, 13636-13663. [CrossRef]

16. Chaour, I.; Fakhfakh, A.; Kanoun, O. Enhanced Passive RF-DC Converter Circuit Efficiency for Low RF Energy Harvesting. Sensors 2017, 17, 546. [CrossRef] [PubMed]

17. Scorcioni, S.; Larcher, L.; Bertacchini, A. Optimized CMOS RF-DC converters for remote wireless powering of RFID applications. In Proceedings of the 2012 IEEE International Conference on RFID (RFID), Orlando, FL, USA, 3-5 April 2012; pp. 47-53.

18. De Carli, L.G.; Juppa, Y.; Cardoso, A.J.; Galup-Montoro, C.; Schneider, M.C. Maximizing the Power Conversion Efficiency of Ultra-Low-Voltage CMOS Multi-Stage Rectifiers. IEEE Trans. Circuits Syst. I Regul. Pap. 2015, 62, 967-975. [CrossRef]

19. Soyata, T.; Copeland, L.; Heinzelman, W. RF Energy Harvesting for Embedded Systems: A Survey of Tradeoffs and Methodology. IEEE Circuits Syst. Mag. 2016, 16, 22-57. [CrossRef]

20. Agrawal, S.; Pandey, S.K.; Singh, J.; Parihar, M.S. Realization of efficient RF energy harvesting circuits employing different matching technique. In Proceedings of the Fifteenth International Symposium on Quality Electronic Design, Santa Clara, CA, USA, 3-5 March 2014; pp. 754-761.

21. Wilas, J.; Jirasereeamornkul, K.; Kumhom, P. Power harvester design for semi-passive UHF RFID Tag using a tunable impedance transformation. In Proceedings of the 2009 9th International Symposium on Communications and Information Technology, Icheon, Korea, 28-30 September 2009; pp. 1441-1445. 
22. Paing, T.; Shin, J.; Zane, R.; Popovic, Z. Resistor Emulation Approach to Low-Power RF Energy Harvesting. IEEE Trans. Power Electron. 2008, 23, 1494-1501. [CrossRef]

23. Dolgov, A.; Zane, R.; Popovic, Z. Power Management System for Online Low Power RF Energy Harvesting Optimization. IEEE Trans. Circuits Syst. I Regul. Pap. 2010, 57, 1802-1811. [CrossRef]

24. Saini, G.; Sarkar, S.; Arrawatia, M.; Baghini, M.S. Efficient power management circuit for RF energy harvesting with $74.27 \%$ efficiency at $623 \mathrm{nW}$ available power. In Proceedings of the 2016 14th IEEE International New Circuits and Systems Conference (NEWCAS), Vancouver, BC, Canada, 26-29 June 2016; pp. 1-4.

25. Pizzotti, M.; Perilli, L.; del Prete, M.; Fabbri, D.; Canegallo, R.; Dini, M.; Masotti, D.; Costanzo, A.; Franchi Scarselli, E.; Romani, A. A Long-Distance RF-Powered Sensor Node with Adaptive Power Management for IoT Applications. Sensors 2017, 17, 1732. [CrossRef] [PubMed]

26. Barnett, R.E.; Liu, J.; Lazar, S. A RF to DC Voltage Conversion Model for Multi-Stage Rectifiers in UHF RFID Transponders. IEEE J. Solid-State Circuits 2009, 44, 354-370. [CrossRef]

27. Razavi Haeri, A.A.; Karkani, M.G.; Sharifkhani, M.; Kamarei, M.; Fotowat-Ahmady, A. Analysis and design of power harvesting circuits for ultra-low power applications. IEEE Trans. Circuits Syst. I Regul. Pap. 2017, 64, 471-479. [CrossRef]

28. Ou, J.H.; Zheng, S.Y.; Andrenko, A.S.; Li, Y.; Tan, H.Z. Novel Time-Domain Schottky Diode Modeling for Microwave Rectifier Designs. IEEE Trans. Circuits Syst. I Regul. Pap. 2018, 65, 1234-1244. [CrossRef]

29. Marian, V.; Adami, S.E.; Vollaire, C.; Allard, B.; Verdier, J. Wireless Energy Transfer Using Zero Bias Schottky Diodes Rectenna Structures. Adv. Mater. Res. 2011, 324, 449-452. [CrossRef]

30. Saini, G.; Arrawatia, M.; Sarkar, S.; Baghini, M.S. A battery-less power management circuit for RF energy harvesting with input voltage regulation and synchronous rectification. In Proceedings of the 2015 IEEE 58th International Midwest Symposium on Circuits and Systems (MWSCAS), Fort Collins, CO, USA, 2-5 August 2015; pp. 1-4.

31. Marian, V.; Allard, B.; Vollaire, C.; Verdier, J. Strategy for Microwave Energy Harvesting From Ambient Field or a Feeding Source. IEEE Trans. Power Electron. 2012, 27, 4481-4491. [CrossRef]

32. Gasulla, M.; Robert, F.J.; Jordana, J.; Ripoll-Vercellone, E.; Berenguer, J.; Reverter, F. A High-Efficiency RF Harvester with Maximum Power Point Tracking. Proceedings 2018, 2, 1049. [CrossRef]

33. Gasulla, M.; Jordana, J.; Robert, F.-J.; Berenguer, J. Analysis of the Optimum Gain of a High-Pass L-Matching Network for Rectennas. Sensors 2017, 17, 1712. [CrossRef] [PubMed]

34. Gutmann, R.J.; Borrego, J.M. Power Combining in an Array of Microwave Power Rectifiers. IEEE Trans. Microw. Theory Tech. 1979, 27, 958-968. [CrossRef]

35. Gutmann, R.J.; Borrego, J.M. Solar Power Satellite Rectenna Design Study: Directional Receiving Elements and Parallel-Series Combining Analysis; NASA Final Rep. NAS9-15453, Chapter 3; Rensselaer Polytechnic Inst.: Troy, NY, USA, 1978.

36. Reverter, F.; Gasulla, M. Optimal Inductor Current in Boost DC/DC Converters Regulating the Input Voltage Applied to Low-Power Photovoltaic Modules. IEEE Trans. Power Electron. 2017, 32, 6188-6196. [CrossRef]

37. Penella, M.T.; Gasulla, M. Runtime Extension of Low-Power Wireless Sensor Nodes Using Hybrid-Storage Units. IEEE Trans. Instrum. Meas. 2010, 59, 857-865. [CrossRef]

38. Ripoll-Vercellone, E.; Ferrandiz, V.; Gasulla, M. An Add-On Electronic Device to Upgrade Mechanical Gas Meters into Electronic Ones. Proceedings 2018, 2, 1094. [CrossRef] 